statistical association is not revealed in a particular population irrespective of size does not necessarily mean that the

\section{Is big beautiful? The continuing story of ADAM33 and asthma}

\section{S T Holgate, J W Holloway}

\section{Role of ADAM33 in the development and progression of asthma}

$\checkmark$ M he gene encoding $\underline{A} \underline{\text { Disintegrin }}$ And Metalloprotease (A $\bar{D} A M) 33$ was the first asthma susceptibility gene to be discovered by positional cloning. ${ }^{1}$ In 460 families enriched with asthma, linkage analysis using microsatellite markers spaced $\sim 9 \mathrm{cM}$ apart revealed a region on chromosome $20 \mathrm{pl} 3$ that carried one or more asthma genes, achieving a Maximum Lod Score (MLS) of 2.24 at $9.99 \mathrm{cM}$. The addition of further markers at $1.2 \mathrm{cM}$ increased the MLS to 2.94 at $12.1 \mathrm{cM}$ which further rose to 3.93 when bronchial hyperresponsiveness was included in the definition of asthma despite halving the sample size, thereby exceeding the threshold for genome wide significance. Physical mapping, direct cDNA selection, and sequencing of DNA cloned into bacterial artificial chromosomes (BACs) identified 25 candidate genes. Linkage disequilibrium mapping of single nucleotide polymorphisms (SNPs) on 23 genes spanning the peak of linkage together with case-control and family based association analyses revealed that ADAM33 accounted for the linkage signal.

Several features of this initial report raised questions regarding the generalisability of the results. ${ }^{2}$ Firstly, although significant evidence for linkage was observed, this region on chromosome $20 \mathrm{p}$ had not been identified in previous genome wide screens in asthma. Secondly, the initial publication did not have a truly independent replication sample. Thirdly, no single SNP demonstrated significant association in both the UK and US populations that made up the total sample when these were analysed separately. Finally, no functional data regarding the role of associated SNPs in alteration of gene expression and/or function and in the development of asthma phenotypes were presented.

Since 2002 there have been a number of separate replication studies in diverse ethnic populations. The first by Howard et $a l^{3}$ examined eight SNPs in the $3^{\prime}$ portion of $A D A M 33$ reported in the original study to be associated with asthma in four unique asthma populations comprising African American, US white, US Hispanic, and Dutch white populations. Significant associations with at least one SNP and asthma were found in each of the populations $(p=0.0009-0.04)$ with multiple SNPs associating with asthma or its partial phenotypes in some of the populations. Further replication has been reported in separate case-control and family based association studies in Germany, ${ }^{4}$ Korea, and Japan. ${ }^{6}$ However, there are two published studies showing no evidence of association ${ }^{7}$ or weak association. ${ }^{8}$

It is therefore timely that, in this issue of Thorax, Blakey and colleagues report the result of a meta-analysis involving eight separate populations totalling 1299 cases and 1665 controls used in case-control association analysis and 4561 families used in transmission disequilibrium tests (TDTs). ${ }^{9}$ In both types of analysis several SNPs were significantly associated with asthma. The important point the authors made is that, based on allele frequencies for the ST+7 G allele of $84.9 \%$ in the asthmatic population and $79.1 \%$ in the controls and an asthma prevalence of $8 \%$, this SNP would potentially contribute to $\sim 50000$ excess asthma cases in the UK population.

What is important to point out is that most case-control and family based association studies looking for disease related genes in complex disorders are statistically underpowered and that far larger sample sizes are needed. Part of the reason for this is the existence of genetic heterogeneity with any one gene varying in its influence over a disease phenotype between populations with differing genetic backgrounds and differing environmental exposures. ${ }^{10}{ }^{11}$ For example, natural selection may have acted on a disease gene haplotype differentially in different populations as recently described for the IL-4 locus on chromosome 5q31-34. ${ }^{12}$ Another example is the NOD2/CARD 15 gene on chromosome 16 which has been associated with Crohn's disease in some but not all populations. ${ }^{13}$ Because a gene in question is not contributing to the phenotype, but the mode of its influence may be complex involving gene-gene or gene-environmental interactions. ${ }^{14}$ However, as the number of independent studies increases, it would be valuable to accrue the evidence systematically as was reported for linkage analysis for asthma on chromosome 5 (the Consortium on Asthma Genetics). ${ }^{15}$ With the recent establishment of the Network of Excellence for Asthma and Allergy (GA $\left.{ }^{2} \mathrm{LEN}\right)$, there is a unique opportunity to further develop meta-analyses for candidates such as ADAM33. The study by Blakey et al is an excellent example of the power of this approach.

At present the SNPs that cause the dysfunction in ADAM33 predisposing to asthma are not yet clear, although several SNPs (Tl, F+1 and ST+7) are coming through in a number of different studies as being associated with asthma. However, because of the very large degree of linkage disequilibrium between many SNPs in ADAM33 so far identified (possibly in excess of 100), genetics alone is unlikely to cast much further light on the disease related variants although new analytical methodologies are being developed. ${ }^{16}$ Some clues about how ADAM33 may influence the asthma phenotype are emerging. In 200 Dutch patients with asthma who had regular lung function measurements made over 20 years, the rare alleles of the SNPS S-2, T-1 and T-2 of the ADAM33 gene were associated with a significant excess decline in baseline forced expiratory volume in 1 second $\left(\mathrm{FEV}_{1}\right)$ of $23.7-30 \mathrm{ml} / \mathrm{year} .{ }^{17}$ These data imply a role for ADAM33 in airway wall remodelling which is known to contribute to chronic airflow obstruction in moderate to severe asthma. ${ }^{18} \mathrm{~A}$ second study conducted in infants born of allergic/asthmatic parents in Northern England ( ${ }^{\mathrm{NAC}}$ MAAS) has revealed positive associations between SNPs of $A D A M 33$ and increased airway resistance measured by plethysmography at age 3 and again at age 5 years, with the strongest effect seen in the homozygotes. ${ }^{19}{ }^{20}$ These data support the idea that alterations in the expression or function of ADAM33 is in some way involved in impairing lung function in early life and, as a consequence, increasing the risk of asthma developing.

The initial study ${ }^{1}$ as well as others ${ }^{3} 5$ have revealed some of the strongest associations when bronchial hyperresponsiveness (BHR) is incorporated into the asthma phenotype. The cellular provenance of ADAM33 mRNA and 
protein in being restricted to mesenchymal cell types (fibroblasts, myofibroblasts and smooth muscle) reinforces the view that this molecule is involved in the pathophysiology of BHR and airway remodelling rather than the immunological or inflammatory components of asthma. ${ }^{121}$ Expression of full length ADAM33 in mammalian cell lines has shown that the metalloprotease domain of ADAM33 is functional $^{22}{ }^{23}$ but the biological targets of the metalloprotease activity are as yet unknown. In cell based sheddase assays ADAM33 functioned as a negative regulator of $\beta$-amyloid precursor peptide (APP) cleavage and mediated some constitutive shedding of stem cell factor (SCF, ckit ligand); however, the kinetics of these cleavage reactions would indicate that these two proteins are not the natural substrates. ${ }^{23}$

Six alternatively spliced variants of ADAM33 in airway fibroblasts have recently been described including one putative secreted variant. ${ }^{24}$ Ninety percent of ADAM33 mRNA is retained in the nucleus and subtle differences in the composition of nuclear and cytoplasmic mRNA indicate important events in both splicing and selecting of ADAM33 transcripts for processing into proteins. What is of great interest is that none of the six variants contain the metalloprotease catalytic domain, suggesting possible other key functions of the molecule-for example, in cell fusion and adhesion. ${ }^{25}$

There is still much to find out about this fascinating and complex molecule in relation to the development and progression of asthma. Added to it are three further new asthma/allergy genes identified by positional cloning: $\mathrm{PDH}$ Finger Protein II (PHF11) on chromosome 13q14 which encodes NY-REN-34, a protein first described in patients with renal cell carcinoma; ${ }^{26}$ dipeptidyl diptidase 10 (DDP10) on chromosome $2 \mathrm{q}_{14}{ }^{27}$ and $G$ protein-coupled receptor for asthma susceptibility (GPRA) on chromosome $7 \mathrm{p} .{ }^{28}$ For each of these genes, as for ADAM 33, determining normal functions and how these are disordered in asthma related alleles is the real future challenge. We are now entering the new research era of translational science and the rebirth of experimental medicine as a research focus. ${ }^{29}$

Thorax 2005;60:263-264.

doi: $10.1136 /$ thx.2004.031385

\section{Authors' affiliations}

S T Holgate, J W Holloway, Allergy and Inflammation Research, Division of Infection, Inflammation and Repair, School of Medicine, Southampton General Hospital, Southampton SO16 6YD, UK

J W Holloway, Division of Human Genetics, School of Medicine, Southampton General Hospital, Southampton SO16 6YD, UK

Correspondence to: Professor S T Holgate, Allergy and Inflammation Research, MP810 Level D, Centre Block, Southampton General Hospital, Southampton SO16 6YD, UK; sth@ soton.ac.uk

\section{REFERENCES}

1 Van Eerdewegh P, Little RD, Dupuis J, et al. Association of the ADAM-33 gene with asthma and bronchial hyper-responsiveness. Nature 2002;418:426-30.

2 Weiss ST, Raby BA. Asthma genetics 2003. Hum Mol Genet 2004; 13:R83-9.

3 Howard TD, Postma DS, Jongepier $\mathrm{H}$, et al. Association of a disintegrin and metalloprotease 33 (ADAM33) gene with asthma in ethnically diverse populations. J Allergy Clin Immunol 2003; 1 12:717-22.

4 Werner M, Herbon N, Gohlke H, et al. Asthma is associated with single-nucleotide polymorphisms in ADAM 33. Clin Exp Allergy 2004;34:26-31.

5 Lee J-H, Park H-S, Park SW, et al. ADAM33 polymorphism: association with bronchial hyperresponsiveness in Korean asthmatics. Clin Exp Allergy 2004;34:860-5.

6 Sakagami T, Hasegawa $\mathrm{T}$, Yoshizawa $\mathrm{H}$, et al. ADAM 33 polymorphisms are associated with aspirin intolerant asthma in Japanese population. Am J Respir Crit Care Med 2003;167:A750.

7 Lind DL, Choudhry S, Ung N, et al. ADAM33 is not associated with asthma in Puerto Rican or Mexican populations. Am J Respir Crit Care Med 2003; 168:1312-6.

8 Raby BA, Silverman EK, Kwiatkowski DJ, et al. ADAM33 polymorphisms and phenotype associations in childhood asthma. J Allergy Clin Immunol 2004;113:1071-8.

9 Blakey J, Halapi E, Bjornsdottir US, et al. Contribution of ADAM 33 polymorphisms to the population risk of asthma. Thorax 2005;60:274-6.

10 Cookson W. A new gene for asthma: would you ADAM and Eve it? Trends Genet 2003; 19:169-72.
11 loannidis JP, Ntzani EE, Trikalinos TA, et al. Replication validity of genetic association studies. Nat Genet 2001;29:306-9.

12 Sakagami T, Witherspoon DJ, Nakaijma T, et al. Local adaptation and population differentiation at the interleukin 13 and interleukin 4 loci. Genes Immun 2004;5:389-97.

13 Arnott ID, Nimmo ER, Drummond HE, et al. NOD2/CARD15, TLR4 and CD1 4 mutations in Scottish and Irish Crohn's disease patients: evidence for genetic heterogeneity within Europe? Genes Immun 2004;5:417-25.

14 Vercelli D. Genetics, epigenetics, and the environment: switching, buffering, releasing. $J$ Allergy Clin Immunol 2004;1 13:381-6.

15 Lonjou C, Barnes K, Chen H, et al. A first trial of retrospective collaboration for positional cloning in complex inheritance: assay of the cytokine region on chromosome 5 by the Consortium on Asthma Genetics (COAG). Proc Natl Acad Sci USA 2000;97:10942-7.

16 Bureau A, Dupuis J, Falls K, et al. Identifying SNPs predictive of phenotype using random forests. Genet Epidemiol 2005;28:171-82.

17 Jongepier H, Boezen HM, Dijkstra A, et al. Polymorphisms of the ADAM33 gene are associated with accelerated lung function decline in asthma. Clin Exp Allergy 2004;34:757-60.

18 Bel EH. Clinical phenotypes of asthma. Curr Opin Pulm Med 2004; 10:44-50.

19 John S, Jury FAC, Holloway J, et al. ADAM33 polymorphisms predict early-life lung function: a population based cohort study. Am J Hum Genet 2003;73:209.

20 Simpson A, Jury F, Cakebread J, et al. Manchester Asthma and Allergy Study: polymorphisms in ADAM 33 predict lung function at age 5 years. J Allergy Clin Immunol 2004; 113:S340

21 Umland SP, Garlisi CG, Shah H, et al. Human ADAM33 messenger RNA expression profile and post-transcriptional regulation. Am J Respir Cell Mol Biol 2003;29:571-82.

22 Garlisi CG, Zou J, Devito KE, et al. Human ADAM33: protein maturation and localization. Biochem Biophys Res Commun 2003;301:35-43.

23 Zou J, Zhu F, Liu J, et al. Catalytic activity of human ADAM33. J Biol Chem 2004;279:9818-30.

24 Powell RM, Wicks J, Holloway JW, et al. The splicing and fate of ADAM33 transcripts in primary human airways fibroblasts. Am J Respir Cell Mol Biol 2004;31:13-21.

25 Cakebread JA, Haitchi HM, Holloway JW, et al. The role of ADAM33 in the pathogenesis of asthma. Springer Semin Immunopathol 2004;25:361-75.

26 Zhang Y, Leaves NI, Anderson GG, et al. Positional cloning of a quantitative trait locus on chromosome 13ql 4 that influences immunoglobulin E levels and asthma. Nat Genet 2003;34:181-6.

27 Allen M, Heinzmann A, Noguchi E, et al. Positional cloning of a novel gene influencing asthma from chromosome $2 q 14$. Nat Genet 2003;35:258-63.

28 Laitinen T, Polvi A, Rydman P, et al. Characterization of a common susceptibility locus for asthma-related traits. Science 2004;304:300-4.

29 Wills-Karp M, Ewart SL. Time to draw breath: asthma-susceptibility genes are identified. Nat Rev Genet 2004;5:376-87. 
$\mathrm{NO}$, hypoxia, and superoxide

\section{Nitric oxide, hypoxia, and superoxide: the good, the bad, and the ugly!}

\section{R A Dweik}

\section{A possible role for $\mathrm{NO}$ in ARDS}

$\mathrm{N}$ tric oxide (NO) is endogenously synthesised by nitric oxide synthases (NOS) which convert L-arginine to L-citrulline and NO. Three NOS isoforms (types I, II and III) have been identified and all of them are expressed in the human lung. ${ }^{1-8}$ NOS I (nNOS) and III (eNOS) are constitutively expressed in tissues and are dependent on increases in intracellular calcium for enzyme activation while NOS II (iNOS) is an inducible form that is calcium independent (table 1). ${ }^{9}$ All NOS isoforms require oxygen, NADPH, FAD, FMN, tetrahydrobiopterin, and calmodulin for activity. ${ }^{1}$ NO is recognised to have a key role in virtually all aspects of lung biology and has been implicated in the pathophysiology of lung diseases. ${ }^{14610-15}$ It is involved in pulmonary neurotransmission, host defence and bacteriostasis, airway and vascular smooth muscle relaxation, pulmonary capillary leak, inflammation, mucociliary clearance, airway mucus secretion, and cytotoxicity. ${ }^{4}{ }^{6} 14$

Cellular sources of NO in the lung include epithelial cells, endothelial cells of pulmonary arteries and veins, inhibitory non-adrenergic non-cholinergic neurones, smooth muscle cells, mast cells, mesothelial cells, fibroblasts, neutrophils, lymphocytes, and macrophages. $^{46^{14}}$ Specifically, NOS I is located in inhibitory non-adrenergic non-cholinergic neurones in the lung while NOS III is found in endothelial cells and the brush border of ciliated epithelial cells. ${ }^{157}$ NOS II is found in the epithelial cells of the airway. Although NOS II may be induced in several types of cells in response to cytokines, endotoxin, or reactive oxygen species, it is continuously expressed in normal human airway epithelium at basal airway conditions. ${ }^{8}{ }^{16}$

Once produced, NO is freely diffusible and enters target cells activating soluble guanylate cyclase to produce guanosine $3^{\prime}, 5^{\prime}$-cyclic monophosphate (cGMP) which mediates most of the physiological effects of NO on smooth muscle including vasodilation and bronchodilation. $^{211}$ NO reaction products may also mediate other physiological and pathological functions in the lungs and many other organ systems. Due to the high reactivity, NO participates in a wide variety of reactions at different sites within the cell, lung tissue, extracellular fluids, and intravascular compartments. Primary reactions that may involve NO intracellularly and extracellularly include its reaction with oxygen, superoxide, haemoglobin, another molecule of NO, enzymes containing iron-sulfur centres, heme-containing proteins, and thiol proteins. ${ }^{12}$ Notably, NO undergoes a direct bimolecular reaction with superoxide $\left(\mathrm{O}_{2}{ }^{-}\right)$yielding peroxynitrite $\left(\mathrm{ONOO}^{-}\right)$at a rate that is even faster than the dismutation of $\mathrm{O}_{2}$ by superoxide dismutases (SOD), which puts NO at the epicentre of oxidative metabolism and inflammation.

\section{REGULATION OF NO SYNTHESIS BY OXYGEN}

All NOS isoforms require the presence of oxygen for activity. ${ }^{9}$ Although it is recognised that oxygen is a substrate for NOS, its effects on the regulation of NOS activity are more complex than a simple enzyme-substrate interaction. ${ }^{4}{ }^{17}$
Interestingly, the effect of hypoxia on NO levels in the airway is primarily a result of airway and alveolar oxygen tension rather than vascular oxygen tension. ${ }^{1819}$ One proposed mechanism(s) for oxygen regulation of NOS activity is outlined in fig 1 . NOS activity during the steady state includes an active cycle (A) that generates $\mathrm{NO}$ and an inactive cycle (B) that involves formation and decay of a heme-NO complex. In the active cycle, oxygen binding to ferrous heme $\left(\mathrm{Fe}^{2+}\right)$ is limiting for enzyme activity. In contrast, resolution of the inactive cycle and entry into the active cycle is oxygen-dependent due to effects on the stability of the heme-NO complex. This includes a reaction between the heme-NO complex and oxygen which results in loss of the heme-NO complex (fig 1). ${ }^{17}$

The oxygen concentration in intact tissues ranges from 1 to $150 \mu \mathrm{M},{ }^{4120}$ with the highest levels found in the lung. Airway epithelial cells are unique in their exposure to oxygen since, above a thin layer of epithelial lining fluid, the airway cells are exposed directly to air containing $21 \%$ oxygen. Based on oxygen solubility and the low differential oxygen gradient between overlying fluid to intracellular endoplasmic reticulum $(1-2 \mu \mathrm{M}),{ }^{4}$ the levels of oxygen in airway epithelial cells may actually approach $260 \mu \mathrm{M}$. Thus, the Michaelis constant $\left(\mathrm{K}_{\mathrm{M}_{2}}\right)$ determined for NOS II $(135 \mu \mathrm{M})$, but not NOS III $(4 \mu \mathrm{M})$ or NOS I $(400 \mu \mathrm{M})$, is well within the physiological range of oxygen concentrations in lung epithelial cells. Importantly, $\mathrm{K}_{\mathrm{M}_{2}}$ for $\mathrm{NO}$ synthesis in the intact human lung $(190 \mu \mathrm{M})$ is similar to NOS II $\mathrm{K}_{\mathrm{MO}_{2}}$ in vitro. ${ }^{3421}$

\section{REGULATION OF NOS GENE EXPRESSION BY OXYGEN}

The immediate effects of short term changes in oxygen concentration on the

\section{Abbreviations: ARDS, acute respiratory distress syndrome; FAD, flavin adenine dinucleotide; FMN, flavin mononucleotide; $\mathrm{K}_{\mathrm{M}} \mathrm{O}_{2}$, Michaelis constant; NADPH, reduced nicotinamide-adenine dinucleotide phosphate; $\mathrm{NO}$, nitric oxide; NOS, nitric oxide synthase; $\mathrm{O}_{2}{ }^{-}$, superoxide; $\mathrm{ONOO}^{-}$, peroxynitrite; ROS, reactive oxygen species; SOD, superoxide dismutases}

Table 1 Nitric oxide synthase enzymes

\begin{tabular}{lllllll}
\hline NOS isoforms & $\begin{array}{l}\text { Numerical } \\
\text { designation }\end{array}$ & Other designation & Expression & Regulation & NO output & Chromosome \\
\hline $\begin{array}{l}\text { Type I } \\
\text { Type II }\end{array}$ & 1 & nNOS & $\begin{array}{l}\text { Constitutive } \\
\text { Inducible }\end{array}$ & $\begin{array}{l}\text { Calcium/CaM } \\
\text { Induced by cytokines, High (nanomol) } \\
\text { indotoxin, and } \\
\text { oxidants } \\
\text { Calcium/CaM }\end{array}$ & $\begin{array}{l}\text { Low (picomol) } \\
17\end{array}$ \\
Type III & 2 & eNOS & Constitutive & Los & 7
\end{tabular}

NO, nitric oxide; NOS, nitric oxide synthase; nNOS, neural nitric oxide synthase; iNOS, inducible nitric oxide synthase; eNOS, endothelial nitric oxide synthase $\mathrm{CaM}$, calmodulin. 


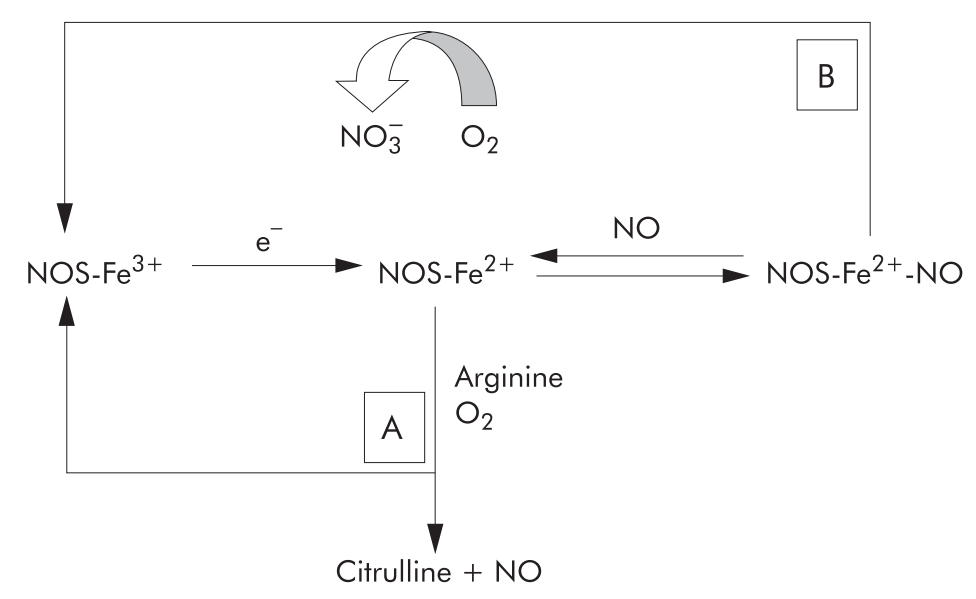

Figure 1 Simplified proposed mechanism of oxygen regulation of NOS enzyme kinetics. NOS activity during the steady state includes an active cycle (A) that generates $\mathrm{NO}$ and an inactive cycle (B) that involves formation and decay of a heme-NO complex. In the active cycle, oxygen binding to ferrous heme $\left(\mathrm{Fe}^{2+}\right)$ is limiting for enzyme activity. In contrast, resolution of the inactive cycle and entry into the active cycle is oxygen-dependent due to effects on the heme-NO complex stability. This includes a reaction between the heme-NO complex and oxygen, which results in loss of the heme-NO complex.

activity of NOS enzymes are probably due to the effects of oxygen on NOS enzyme kinetics. However, prolonged hypoxia can have significant effects on the gene expression of the different NOS isoforms. ${ }^{23} 21-23$ These transcriptional effects may vary among species or among organ systems in the same species. ${ }^{2}{ }^{21}$ For example, while hypoxia produces a progressive decline in constitutive NOS mRNA levels in bovine pulmonary artery endothelial cells, ${ }^{22-24}$ chronic hypoxia upregulates constitutive NOS expression in rabbit heart ${ }^{25}$ and rat lung pulmonary arteries. ${ }^{26}$ Chronic hypoxia also increases NOS

expression and NOS activity in rat carotid bodies. ${ }^{27}$

In this issue of Thorax, Muzaffar et al ${ }^{28}$ describe the effect of hypoxia on the expression of endothelial nitric oxide synthase (NOS III) and gp91 ${ }^{\text {phox }}$ (the active catalytic subunit of NADPH oxidase), and the formation of superoxide in pig pulmonary artery segments, pulmonary artery smooth muscle cells, and pulmonary artery endothelial cells. They incubated pulmonary artery segments (with and without intact endothelium) and cells (endothelial and smooth muscle cells) in the absence of ambient oxygen for 2 hours and

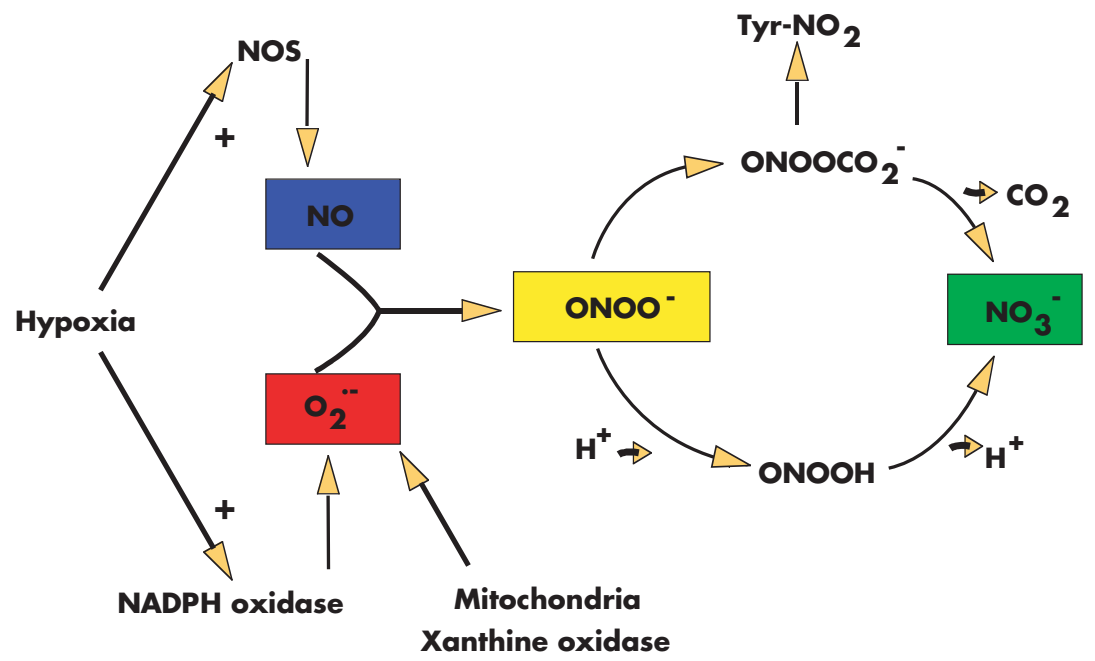

Figure 2 Simplified proposed model of NO reaction with superoxide $\left(\mathrm{O}^{-}\right)$. NO undergoes a direct bimolecular reaction with $\mathrm{O}_{2}^{-}$yielding peroxynitrite $\left(\mathrm{ONOO}^{-}\right)$at almost diffusion limited rates $\left(k=6.7-19 \times 10^{9} / \mathrm{M} / \mathrm{s}\right)$. The rate constant is over 3.5 times faster than the dismutation of $\mathrm{O}_{2}{ }^{-}$by superoxide dismutases. By rapidly consuming superoxide, $\mathrm{NO}$ produces $\mathrm{ONOO}^{-} /$ $\mathrm{ONOOH}$, a far less reactive oxidant than superoxide that can be further metabolised to innocuous products like $\mathrm{NO}_{3}{ }^{-}$. Tyr- $\mathrm{NO}_{2}$, nitrotyrosine. measured the formation of superoxide by ferricytochrome c reduction. They also measured the expression of proteins by Western blotting and immunocytochemistry. The absence of oxygen in the ambient air promoted the formation of superoxide in the studied tissues and cells. Various enzyme inhibitors were used to determine the source of superoxide production. They also pre-incubated the cells with several inflammatory mediators to determine if they could enhance the effects of hypoxia. A summary of the findings is that hypoxia upregulates NADPH oxidase and NOS III resulting in increased production of superoxide, NO, and peroxynitrite in their system.

A major component missing in the model studied by Muzaffar and colleagues is the role of NOS II. In humans NOS II is continuously expressed in the airway epithelium, is a major source of NO in the lung, and appears to be the most responsive to hypoxia in the physiological range. ${ }^{23} 21$ Due to the free diffusion of $\mathrm{NO}$ and the close apposition of airways to pulmonary vessels, endogenous NO production in the airways can have significant effects on the pulmonary vessels. The authors comment on both eNOS (NOS III) and iNOS (NOS II) throughout the paper, but their system does not seem to be appropriate for the study of NOS II which is mainly expressed in the airway epithelium (which the authors did not study) and not in the endothelium or smooth muscle (reported here). The cells they studied do not express NOS II in detectable levels at baseline and that does not change with hypoxia. So, the additional use of NOS II inhibitors does not add much. While the authors emphasise the relevance of their findings to acute respiratory distress syndrome (ARDS), the link is rather speculative. They studied healthy piglets and evaluated their pulmonary artery rings or cells in isolation from the rest of the lung. Although they used preincubation with some inflammatory markers as a suggestion as to what happens in ARDS, it would have been more appropriate to study rings from piglets with and without ARDS. The weak link to ARDS, however, does not diminish the relevance of the findings.

\section{NO-SUPEROXIDE INTERACTION}

Free radicals/reactive oxygen species (ROS) may be toxic in two ways. They can interact with metal or organic redox centres and promote irreversible oxidation reactions inactivating the target metabolic process, or they can initiate reactions which then become self-sustaining through the generation of propagating radicals. In either case, this can 
result in deleterious effects on the cell. The most effective protection against oxidant mediated tissue damage is to scavenge the initiating radical. ${ }^{15} 29$ Although NO is itself a radical, many of the same chemical and physical properties of NO that allow it to exert oxidant effects can also result in antioxidant actions. The role of $\mathrm{NO}$ as an oxidant or an antioxidant probably depends on the local tissue milieu. In an environment where the oxidant load is low, the highly reactive properties of NO give the molecule oxidant properties. However, in situations where the oxidant load is high (as in asthma and ARDS), NO plays an antioxidant role by scavenging superoxide and other ROS. NO undergoes a direct bimolecular reaction with $\mathrm{O}_{2}{ }^{-}$yielding $\mathrm{ONOO}^{-}$at almost diffusion limited rates (rate constant $\left.(k)=6.7-19 \times 10^{9} / \mathrm{M} / \mathrm{s}\right) .^{12}$ The rate constant is over 3.5 times faster than the dismutation of $\mathrm{O}_{2}{ }^{--}$by SOD. By rapidly consuming superoxide, NO produces $\mathrm{ONOO}^{-} / \mathrm{ONOOH}$, a far less reactive oxidant than superoxide that can be further metabolised to innocuous products like $\mathrm{NO}_{3}{ }^{-}$(fig 2). ${ }^{12}{ }^{30}$

Muzaffar and colleagues speculate that the upregulation of two enzymes with opposite effects may represent a protective mechanism to counteract the effect of hypoxia or a pathological mechanism leading to the progression of ARDS. There are no data in their study to favour one explanation over the other. However, based on models in other diseases and on our knowledge of the biology of $\mathrm{NO}$ and reactions in the lung, one would suspect that, if hypoxia upregulated NADPH oxidase without simultaneously upregulating NOS expression, the increased release of superoxide $\left(\mathrm{O}_{2}{ }^{-}\right)$would go unchecked resulting in serious tissue injury. By reacting with superoxide to form peroxynitrite $\left(\mathrm{ONOO}^{-}\right)$, NO produced by NOS serves as a scavenger of superoxide resulting in a net antioxidant effect (fig 2). The simultaneous upregulation of NOS is therefore probably a protective feature. Although the link to ARDS remains speculative, these findings have potential implications for a wide variety of lung diseases from asthma to pulmonary hypertension ${ }^{12} 13153132$ in which oxidative stress and/or hypoxia have a role.

Thorax 2005;60:265-267.

doi: $10.1136 /$ thx.2004.038471

Correspondence to: Dr R A Dweik, Department of Pulmonary, Allergy, and Critical Care Medicine, The Cleveland Clinic Foundation, 9500 Euclid Avenue/A90, Cleveland, Ohio 44195, USA; dweikr@ccf.org

Dr Dweik is supported by the National Institutes of Health grant NIH-HL68863.

\section{REFERENCES}

1 Dweik RA, Laskowski D, Ozkan M, et al. High levels of exhaled nitric oxide (NO) and NO synthase III expression in lesional smooth muscle in lymphangioleiomyomatosis. Am J Respir Cell Mol Biol 2001;24:414-8.

2 Dweik RA, Erzurum SC. Effects of nitric oxide and cyclic GMP on smooth muscle cell proliferation. In: Moss J, ed. LAM and other diseases characterized by smooth muscle cell proliferation (Lung Biology in Health and Disease). New York: Marcel Dekker, 1999:333-49.

3 Dweik RA, Erzurum SC. Regulation of nitric oxide (NO) synthases and gas phase NO by oxygen. In: Marczin N, Kharitonov SA, Yacoub MH Barnes PJ, eds. Disease markers in exhaled breath (Lung Biology in Health and Disease). New York: Marcel Dekker, 2003:235-46.

4 Dweik RA Laskowski D, Abu-Soud HM, et al. Nitric oxide synthesis in the lung. Regulation by oxygen through a kinetic mechanism. J Clin Invest 1998;101:660-6.

5 Dweik RA, Guo FH, Uetani K, et al. Nitric oxide synthase in the human airway epithelium Zhongguo Yao Li Xue Bao 1997; 18:550-2.

6 Nathan C, Xie QW. Nitric oxide synthases: roles, tolls, and controls. Cell 1994;78:915-8.

7 Kobzik L, Bredt DS, Lowenstein CJ, et al. Nitric oxide synthase in human and rat lung: immunocytochemical and histochemical localization. Am J Respir Cell Mol Biol 1993:9:371-7.

8 Guo FH, Uetani K, Haque SJ, et al. Interferon gamma and interleukin 4 stimulate prolonged expression of inducible nitric oxide synthase in human airway epithelium through synthesis of soluble mediators. J Clin Invest 1997; 100:829-38.

9 Stuehr DJ. Mammalian nitric oxide synthases. Biochim Biophys Acta 1999;1411:217-30.

10 Dweik RA. The promise and reality of nitric oxide in the diagnosis and treatment of lung disease. Cleve Clin J Med 2001;68:486, 488, 490, 493.

11 Dweik RA. Pulmonary hypertension and the search for the selective pulmonary vasodilator. Lancet 2002;360:886-7.

12 Dweik RA, Comhair SA, Gaston B, et al. NO chemical events in the human airway during the immediate and late antigen-induced asthmatic response. Proc Natl Acad Sci USA 2001;98:2622-7.

13 Khatri SB, Hammel J, Kavuru MS, et al. Temporal association of nitric oxide levels and airflow in asthma after whole lung allergen challenge. J Appl Physiol 2003;95:436-40.

14 Schmidt HH, Walter U. NO at work. Cell 1994;78:919-25.
15 Ozkan M, Dweik RA. Nitric oxide and airway reactivity. Clin Pulmon Med 2001;8:199-206.

16 Guo FH, De Raeve HR, Rice TW, et al. Continuous nitric oxide synthesis by inducible nitric oxide synthase in normal human airway epithelium in vivo. Proc Natl Acad Sci USA 1995;92:7809-13.

17 Abu-Soud HM, Rousseau DL, Stuehr DJ. Nitric oxide binding to the heme of neuronal nitricoxide synthase links its activity to changes in oxygen tension. J Biol Chem 1996;271:32515-8

18 Ide H, Nakano H, Ogasa T, et al. Regulation of pulmonary circulation by alveolar oxygen tension via airway nitric oxide. J Appl Physiol 1999:87:1629-36.

19 Grimminger F, Spriestersbach R, Weissmann N, et al. Nitric oxide generation and hypoxic vasoconstriction in buffer-perfused rabbit lungs. J Appl Physiol 1995;78:1509-15.

20 Vanderkooi JM, Erecinska M, Silver IA. Oxygen in mammalian tissue: methods of measurement and affinities of various reactions. Am J Physiol 1991;260:C1131-50.

21 Dweik RA. Nitric oxide production in the lung and its regulation by oxygen. In: Marczin N, Yacoub MH, eds. Disease markers in exhaled breath: basic mechanisms and clinical applications (NATO Science Series). Amsterdam, Netherlands: IOS Press, 2002:11-17.

22 Liao JK, Zulueta JJ, Yu FS, et al. Regulation of bovine endothelial constitutive nitric oxide synthase by oxygen. J Clin Invest 1995;96:2661-6.

23 Melillo G, Musso T, Sica A, et al. A hypoxiaresponsive element mediates a novel pathway of activation of the inducible nitric oxide synthase promoter. J Exp Med 1995; 182:1683-93.

24 Phelan MW, Faller DV. Hypoxia decreases constitutive nitric oxide synthase transcript and protein in cultured endothelial cells. J Cell Physiol 1996; 167:469-76

25 Baker JE, Holman P, Kalyanaraman B, et al. Adaptation of hearts to chronic hypoxia increases tolerance to subsequent ischemia by increased nitric oxide production. Adv Exp Med Biol 1998;454:203-17

26 Sato K, Rodman DM, McMurtry IF. Hypoxia inhibits increased ETB receptor-mediated NO synthesis in hypertensive rat lungs. Am J Physiol 1999;276:L571-81.

27 Di Giulio C, Di Muzio M, Sabatino G, et al. Effect of chronic hyperoxia on young and old rat carotid body ultrastructure. Exp Gerontol 1998;33:319-29.

28 Muzaffar S, Shukla N, Angelini GD, et al. Acute hypoxia simultaneously induces the expression of gp9 $1^{\text {phox }}$ and endothelial nitric oxide synthase in the porcine pulmonary artery. Thorax 2005;60:305-13.

29 Freeman BA, White CR, Gutierrez $\mathrm{H}$, et al. Oxygen radical-nitric oxide reactions in vascular diseases. Adv Pharmacol 1995;34:45-69.

30 Dweik RA. Nitric oxide reactions in the asthmatic airway. In: Marczin N, Yacoub MH, eds. Disease markers in exhaled breath: basic mechanisms and clinical applications (NATO Science Series) Amsterdam, Netherlands: IOS Press, 2002:159-66.

31 Ghamra ZW, Dweik RA. Primary pulmonary hypertension: an overview of epidemiology and pathogenesis. Cleve Clin J Med 2003;70(Suppl 1):S2-8.

32 Kaneko FT, Arroliga AC, Dweik RA, et al. Biochemical reaction products of nitric oxide as quantitative markers of primary pulmonary hypertension. Am J Respir Crit Care Med 1998; 158:917-23. 
Early diagnosis of lung cancer

\section{Symptoms and the early diagnosis of lung cancer}

\section{S S Birring, M D Peake}

\section{Significant delays remain in the diagnosis of lung cancer}

$\mathrm{L}$ ung cancer is the leading cause of cancer death in the western world, -resulting in nearly 30000 deaths in England and Wales in 2002. ${ }^{1}$ Advances in the management of breast, cervical, and prostate cancer have led to improved survival rates, whereas mortality from lung cancer has remained largely unchanged. ${ }^{2}$ Even the best reported 5 year survival rates for lung cancer are only $10-15 \%^{34}$ and, in England, in patients diagnosed between 1993 and 1995 the survival rate was only $5.5 \%$ at 5 years and $22 \%$ at 1 year. ${ }^{5}$

This high mortality is very largely a consequence of patients presenting late when the cancer is already locally advanced or has disseminated. Around $80 \%$ of patients with lung cancer have stage III or IV disease at presentation, therefore excluding them from potentially curative surgical resection. ${ }^{6}$ Detection of the tumour at an earlier stage leads to an improved prognosis, patients presenting with stage IA nonsmall cell lung cancer and undergoing surgical resection having a 5 year survival of around $60 \%$.

Patients can (and usually do) live with lung cancer for many years before it becomes apparent. Early lung cancer is largely asymptomatic and internalisation of tumours means patients are not alerted by obvious physical changes. It takes around 8 years for a squamous cell carcinoma, for example, to reach a size of $30 \mathrm{~mm}$ when it is most commonly diagnosed so, by the time symptoms arise, the risk of metastasis is considerable. ${ }^{89}$ Once symptoms appear they are often ignored by patients, delaying the diagnosis and treatment even further. The reasons for patient delay in diagnosis are poorly understood.

Lung cancer can present with a wide range of symptoms, the most common being cough, haemoptysis, chest and shoulder pain, dyspnoea, hoarseness, weight loss, anorexia, fever, weakness, and bone pain. ${ }^{10}$ Guidelines based on this pattern of symptoms have been developed ${ }^{11}$ and stress that the physician needs to be alert to the possibility of lung cancer in patients with such symptoms, particularly if they are persistent and occur in those at higher risk of lung cancer-for example, smokers and ex-smokers, especially those over the age of 50 and with chronic airflow obstruction. Unfortunately, symptoms of lung cancer are largely non-specific and recognition of new symptoms is more difficult in the presence of co-existing respiratory disease such as chronic obstructive pulmonary disease. In addition, the evidence base for these guidelines (and the forthcoming updated NICE version) is weak and contains no data on the predictive value of symptoms or symptom complexes for the presence or absence of lung cancer in a primary care based population.

In this issue of Thorax Corner and colleagues present the findings of an exploratory retrospective interview study commissioned by the Department of Health's policy research programme investigating patient delays in cancer diagnosis. ${ }^{12}$ Detailed interviews were carried out in 22 patients after diagnosis but before treatment to obtain a pre-diagnosis symptom history. This history was compared with primary care and hospital records. Cough and dyspnoea were found to be the most common symptoms among a wide range reported. All patients experienced at least one new symptom before diagnosis. Although the symptoms were reported as a persistent change in health status, they were not interpreted as being serious at their onset. The median interval from the initial change in health status and the symptom prompting the first visit to the general practitioner was found to be 7 months, with a further average delay of 5 months to diagnosis. Interestingly, there were no significant differences in delays to diagnosis according to operability of the tumour.

The findings of the study by Corner $e t$ al, although preliminary, are of interest and confirm that there are significant patient related delays for the diagnosis of lung cancer, longer than those previously reported. Jensen $e t$ a ${ }^{13}$ reviewed the time elapsed from symptoms to medical attention reported in 16 studies and found a wide variation from 7 days to 6 months. This wide range of patient delay times is likely to be a result of many factors, including socioeconomic, cultural and health care differences. The reasons why patients did not interpret their symptoms as serious or seek medical attention sooner are not reported by Corner et al and need further investigation. The most plausible explanation for this is that, while reported symptoms were new, they were too nonspecific-especially in the context of coexisting respiratory disease-to raise alarm. A limitation of the data reported by Corner et al is that there is no objective validation of the presence and timing of symptoms reported before the first consultation with the GP. Patients, with hindsight of the diagnosis, may look for explanations and re-examine past events which we recognise in other clinical situations are often false. Prospective studies of the specificity and predictive value of reported symptoms for the diagnosis of lung cancer and their prevalence in high risk individuals would be required to answer these questions, although such studies are complex, expensive, and long term. Other factors that may contribute to patient delays in diagnosis include denial, fear, guilt, other psychosocial issues, poor public health education, and issues relating to access to health care. The fact that the patients in this study did not interpret the early changes as potentially serious may also mean that they were reluctant to bother their GPs with what they considered "trivial" complaints. Bowen et al ${ }^{14}$ studied factors influencing patient delays and found that male patients had longer delays, over half of all patients needed encouragement from family or friends to see their GP, and 75\% were not aware of the significance of their symptoms and had not received any advice about them. Future studies also need to explore how patients respond to changes in health status, why patients with lung cancer appear to have such relatively little contact with their GP, and whether improved public awareness of lung cancer symptoms and easier access to a wider variety of sources of healthcare advice could contribute to achieving earlier diagnosis with a consequent improvement in survival.

Attempts should be made to develop public health education programmes promoting awareness of lung cancer, a process which needs to be accompanied by the presentation of a more positive image of lung cancer, stressing the fact that early diagnosis saves lives rather than perpetuating the negative image that the current prognosis for the majority of patients is so poor. 
Early symptom recognition in lung cancer will only be worthwhile if it improves outcomes for patients, especially survival. Christensen et al ${ }^{15}$ found that, for patients with operable lung cancer (stage I/II), the interval between the trigger symptom initiating contact with the healthcare system and the time of operation was significantly shorter than the time between the trigger symptom and the decision not to operate for patients with stage III/IV disease. In contrast, Mydral et $a l^{16}$ found the time from onset of symptoms to treatment was shorter in patients with stage IV lung cancer (median 3.4 months) than in those with stage I/II disease (median 5.5 months). This is likely to result from the fact that patients with advanced disease had more severe symptoms and signs and received more rapid treatment. The current study by Corner et al ${ }^{12}$ did not find differences in patient delay times according to the stage of lung cancer, but the numbers studied were insufficient to answer this question. Studies investigating the effect of hospital delays in diagnosis and treatment on prognosis similarly report conflicting results. Comparison of the data in these studies is, however, made difficult by the differing definitions of patient delays and clinical differences of patient groups studied. ${ }^{17-19}$

Because of the non-specific nature of the symptoms in question and the fact that a paradigm shift in the behaviour of the population at most risk of developing lung cancer is highly unlikely, attempts at making major progress on early referral at a population level based on symptoms alone seem very unlikely to be successful. Other methods of early detection therefore need to be energetically explored to lower the stage at presentation in lung cancer. Screening is an attractive option because there is a relatively well defined high risk population and the potential for curative surgery in early disease. Radiological screening has been the most studied. The screening trials of the 1970/80s with chest radiography were deemed negative, ${ }^{20}$ but the advent of faster spiral and multiple slice CT scanners have led to a renewed interest. Preliminary studies of low dose CT screening show promise and formal trials are underway. ${ }^{21}$ The demonstration of benefits of screening programmes on the overall survival statistics of the studied population is essential before widespread use of this method is adopted. Currently, the improved survival benefits of screening are not known and interpretation of published studies is made difficult since no randomised trial has yet been reported and issues such as lead time and over-diagnosis bias add to the complexity of interpretation. ${ }^{22}$ The natural history of malignant nodules as small as $5 \mathrm{~mm}$ detected on CT scans is not well described and even nodules only $10 \mathrm{~mm}$ in size containing $10^{9}$ cells represent a fairly late stage in the disease process, considering that at death lung cancer tumours typically have $10^{12}$ cells. $^{9}$ The survival benefit of any screening programme must also outweigh the risks related to managing false positive nodules. The optimum strategy for the management of small lesions identified on screening has not been determined

Another potential screening tool is advanced sputum cytology, enhanced by molecular genetics, immunohistochemistry, including the monoclonal antibody staining of antigens expressed by lung cancer cells. ${ }^{23}{ }^{24}$ Autofluorescence bronchoscopy may complement cytology with the potential for the detection of metaplasia and carcinoma in situ in bronchial mucosa. ${ }^{25}$ A multimodality approach may be required to optimise early detection and management of lung cancer from screening programmes and early attempts at this approach look promising. ${ }^{26}$

While efforts consequent upon the National Cancer $\operatorname{Plan}^{27}$ and the Cancer Services Collaborative have helped to reduce hospital delays, the study by Corner et al reminds us that significant delays remain in the diagnosis of lung cancer before the patient ever gets into secondary care. While this is clearly an important area for future research, it is probable that-in the absence of a major advance in treatment or a significant further reduction of cigarette consumption-some form of screening is the intervention most likely to have a major impact on the current poor survival statistics, and it is vital that the major funders of national research programmes grasp this difficult nettle as soon as possible.

Thorax 2005;60:268-269.

doi: $10.1136 /$ thx.2004.032698

\section{Authors' affiliations}

S S Birring, M D Peake, Thoracic Oncology

Unit, Department of Respiratory Medicine,

Glenfield Hospital, Leicester, UK

Correspondence to: Dr M D Peake, Thoracic Oncology Unit and Institute for Lung Health, Department of Respiratory Medicine, Glenfield Hospital, Leicester LE3 9QP, UK; mick.peake@ uhl-tr.nhs.uk

\section{REFERENCES}

1 Office for National Statistics. Mortality statistics cause. Review of the Registrar General on deaths by cause, sex and age, in England and Wales, 2002, Series DH2. London: Office for National Statistics, 2003:29.

2 Fry WA, Phillips JL, Menck HR. Ten year survey of lung cancer treatment and survival in hospitals in the United States: a national cancer database report. Cancer 1999;86:1867-76.

3 SEER. www.seer.gov.

4 Janssen-Heijnen MLG, Gatta G, Forman D, et al. Variation in survival of patients with lung cancer in Europe, 1985-1989. Eur J Cance 1998;34:2191-6.

5 Office for National Statistics. England: Cancer survival, 1993-2000. London: Office for National Statistics, 2001.

6 Pearson FG. Current status of surgical resection for lung cancer. Chest 1994; 106:337S.

7 Mountain CF. Revisions in the Internationa System for Staging Lung Cancer. Chest 1997; 111:1710-7.

8 Geddes DM. The natural history of lung cancer: a review based on tumour growth. $\mathrm{Br} J$ Dis Chest 1979;73:1-17.

9 Weiss ST. Passive smoking and lung cancer. What is the risk? Am Rev Respir Dis 1986; 133: 1-3

10 Hyde L, Hyde CL. Clinical manifestations of lung cancer. Chest 1974;65:298-307.

11 Department of Health. Referral guidelines for suspected cancer. London: Department of Health, 2000

12 Corner J, Hopkinson J, Fitzsimmons D, et al. Is late diagnosis of lung cancer inevitable? Interview study of patients' recollections of symptoms before diagnosis. Thorax 2005;60:314-9.

13 Jensen AR, Mainz J, Overgaard J. Impact of delay on diagnosis and treatment of primary lung cancer. Acta Oncol 2002;41:147-52.

14 Bowen EF, Rayner CF. Patient and GP led delays in the recognition of symptoms suggestive of lung cancer. Lung Cancer 2002;37:227-8.

15 Christensen ED, Harvald T, Jendresen M, et al. The impact of delayed diagnosis of lung cancer on the stage at the time of operation. Eur J Cardiothorac Surg 1997;12:880-4.

16 Myrdal G, Lambe M. Hillerdal G, et al. Effect of delays on prognosis in patients with non-small cell lung cancer. Thorax 2004;59:45-9.

17 O'Rourke N, Edwards R. Lung cancer treatmen waiting times and tumour growth. Clin Oncol 2000;12:141-4.

18 Aragoneses FG, Moreno N, Leon P, et al Influence of delays on survival in the surgical treatment of bronchogenic carcinoma. Lung Cancer 2002:36:59-63.

19 Billing JS, Wells FC. Delays in the diagnosis and surgical treatment of lung cancer. Thorax 1996;51:903-6.

20 Flehinger BJ, Melamed MR, Zaman MB, et al. Early lung cancer detection: results of the initial (prevalence) radiologic and cytologic screening in the Memorial Sloan-Kettering study. Am Rev Respir Dis 1984;130:555-60.

21 Henschke $\mathrm{Cl}, \mathrm{McC}$ auley DI, Yankelevitz DF, et al. Early Lung Cancer Action Project: overall design and findings from baseline screening. Lancet 1999;354:99-105.

22 Mulshine JL, Smith RA. Lung cancer. 2: Screening and early diagnosis of lung cancer, Thorax 2002;57:1071-8.

23 Mao L, Hurban RH, Boyle JO, et al. Detection of oncogene mutations in sputum precedes diagnosis of lung cancer. Cancer Res 1994:54:1634-7.

24 Tockman MS, Gupta PK, Myers JD, et al. Sensitive and specific monoclonal antibody recognition of human lung cancer antigen on preserved sputum cells: a new approach to early lung cancer detection. J Clin Oncol 1988;6:1685-93.

25 Lam S, MacAulay C, LeRiche JC, et al. Detection and localization of early lung cancer by fluorescence bronchoscopy. Cancer 2000;89(Suppl):2468-73.

26 Loewen G, Reid M, Tan DF, et al. Bimodality lung cancer screening in high-risk patients. Chest 2004; 125: 163-4S

27 Department of Health. The NHS National Cancer Plan. London: Department of Health, 2001. 
Lung function estimates in IPF

\section{Lung function estimates in idiopathic pulmonary fibrosis: the potential for a simple classification}

\section{J J Egan, F J Martinez, A U Wells, T Williams}

\section{Application of a classification based on simple lung function testing in IPF}

$F$ or many years the idiopathic pulmonary fibrosis (IPF) community has debated the merits of the histopathological classification of idiopathic interstitial pneumonia (IIP). ${ }^{1}$ The ATS/ERS consensus statement identifies the importance of histological categories of usual interstitial pneumonia (UIP) and non-specific interstitial pneumonia (NSIP). Furthermore, it emphasises that IPF is the clinical correlate of UIP. Despite the recognition of the importance of histological characterisation, surgical biopsy rates vary considerably. ${ }^{2}$ Most clinicians do not subject their patients to surgical biopsy, despite the potential prognostic benefit of detailed histological evaluation, because many patients are elderly and have significantly impaired lung function and other medical co-morbidities resulting in a potentially high mortality rate. ${ }^{3}$ In addition, HRCT scanning provides diagnostic data of high sensitivity and specificity for the diagnosis of IPF with acceptable interobserver variability. ${ }^{4}$

Meanwhile, the chronic obstructive pulmonary disease (COPD) and lung transplantation communities have applied simple but pragmatically useful classifications. Bronchiolitis obliterans syndrome (BOS), for example, has been subject to a clinical grading system reflecting the degree of impairment of lung function following lung transplantation. The emergence of a classification based on simple lung function testing occurred because of the difficulties in obtaining adequate tissue for the diagnosis of obliterative bronchiolitis. This is comparable to the situation in IPF where tissue is also difficult to obtain. The success of the classification of BOS is reflected by the publication of an updated version.

The global initiative for COPD (GOLD) is another example of a consensus classification based on simple lung function testing. GOLD provides a staging system ranging from an "at risk" category to a severe disease category. ${ }^{7}$ Based on simple lung function testing, it is reproducible and has facilitated the identification of patients with COPD. Furthermore, it has enabled worldwide harmonisation of clinical and experimental research studies in COPD. ${ }^{7}$

Recent publications relating to lung function, focusing specifically on IPF, provide a similar opportunity. The histological classification proposed by Katzenstein and endorsed by the ATS/ ERS consensus statement potentially allows for the development of a staging system based on simple and widely available evaluation techniques. The aim of such a classification would not be to supersede the histological classification but rather to build upon it.

The aim of this review is therefore to discuss the potential of a grading system for IPF based solely on simple static lung function studies. For judging disease severity we sought a parameter that identified patients with impaired survival, defined as less than 2 years. For judging disease progression we sought lung function changes which identified patients at increased risk of mortality.

\section{HISTOLOGICAL CLASSIFICATION} AND LUNG FUNCTION

The absence of broad agreement on the interpretation of lung function testing in IPF reflects the variability in published data on the subject (table 1 ). ${ }^{8}$ Impaired survival has been associated with a variety of findings including no relationship with lung function," increased ratio of forced expiratory volume in 1 second to forced vital capacity $\left(\mathrm{FEV}_{\mathrm{l}} / \mathrm{FVC}\right.$ ratio $),{ }^{10}$ reduced total lung capacity (TLC), ${ }^{11} 12$ and change in FVC/carbon monoxide transfer factor (TLCO) after 1 year (table 1$).^{13}$ Formerly a critical confounding factor influencing the interpretation of lung function was the failure to distinguish between histological subsets in IIP. ${ }^{14}{ }^{15}$ Consequently, early published data on lung function have been limited by the absence of focus on specific histological subgroups. Recent publications have therefore focused on lung function data specifically in the context of UIP and NSIP, allowing a consistent theme to emerge (table 1). A PubMed literature search was performed to identify peer reviewed manuscripts relating to lung function testing in IPF published in 1998-2004. This period was chosen because it reflects the clinical impact of the characterisation of patients based on histological subsets as described by Katzenstein et al in 1998. ${ }^{14}$

\section{LUNG FUNCTION AND DISEASE SEVERITY}

A global view of historical lung function data emphasises that a poor outcome is associated with "low" lung function. Schwartz et al $^{12}$ highlighted the fact that reduced lung function was associated with limited survival. In a study of 74 individuals who had undergone lung biopsy, univariate analysis showed that there was a greater hazard of death with lower \% predicted FVC and lower \% predicted TLCo. However, clinicians require a specific threshold in the context of disease severity. ${ }^{16}$ The study by Gay et al $^{17}$ emerged as a key publication in the context of the methodology used for appraising the influence of lung function. In contrast to historical studies which reported group differences in survival and hazard ratios, they applied for the first time receiver operator characteristic (ROC) curve estimates. ROC state the probability that a diagnostic criterion selects a disease subject correctly rather than a non-disease subject. ${ }^{18}$ In the context of lung function, ROC curves express the ability of a variable to discriminate between death and/or survival. However, despite the application of ROC analysis by Gay et al, no lung function variable identified risk of death (table 1). This is likely to reflect the efforts to study well characterised patients, resulting in a relatively small number of subjects in the study.

\section{DISEASE SEVERITY: ADVANCED AND LIMITED DISEASE}

Acknowledging the need for a specific threshold value for estimating disease severity, recent data suggest that severity of disease can be categorised as advanced or limited disease on the basis of lung function. Extending the study by Gay et al by using ROC analysis, Mogulkoc et al ${ }^{19}$ focused on lung function in the context of transplant referral. This study targeted a well characterised group of 115 patients with IPF aged 45-65 years. A total of 12 variables influencing survival were significant on univariate regression analysis. A multivariate stepwise regression analysis identified only \% predicted TLCO and HRCT fibrosis as independent predictors of 2 year survival. ROC analysis of \% 
Table 1 Summary of lung function studies in IPF

\begin{tabular}{|c|c|c|c|c|c|c|c|}
\hline Author & Subset & $\mathbf{N}$ & Age (years) & FVC & TLCO & (Survival months) & Result \\
\hline Schwartz $^{12}$ & No & 38 & 62 & $67 \%$ & $46 \%$ & NA & $\begin{array}{l}\text { Decreased TLC/TLCO associated with } \\
\text { dyspnoea }\end{array}$ \\
\hline Schwartz ${ }^{12}$ & No & 74 & 67 & $62 \%$ & $44 \%$ & 60 & Increased $\mathrm{FEV}_{1} / \mathrm{FVC}$ ratio \\
\hline Hanson $^{13}$ & No & 58 & 59 & $61 \%$ & $42 \%$ & 88 & $\begin{array}{l}1 \text { year: } 10 \% \text { drop FVC, } 20 \% \text { drop TLCO: } \\
\text { increased mortality }\end{array}$ \\
\hline Erbes $^{11}$ & No & 99 & 53 & $89 \%$ & $46 \%$ & 41 & Reduced TLC \\
\hline Hubbard ${ }^{9}$ & No & 244 & 69 & $78 \%$ & $49 \%$ & 34 & No LF variable associated with mortality \\
\hline Gay $^{17}$ & Yes & 38 & 54 & UIP $69 \%$ & UIP $50 \%$ & 26 & No LF variable associated with mortality \\
\hline Mogulkoc ${ }^{19}$ & Yes & 115 & 55 & UIP $72 \%$ & UIP $49 \%$ & 50 & $\begin{array}{l}\text { TLCO } 39 \% \text { predicted: } 80 \% \text { sensitivity/ } \\
\text { specificity } 2 \text { year survival }\end{array}$ \\
\hline Wells $^{27}$ & Yes & 197 & 62 & UIP $68 \%$ & $36 \%$ & 22 & $\begin{array}{l}\text { Mortality associated with reduced TLCO, } \\
\text { FVC, TLC }\end{array}$ \\
\hline Latsi $^{20}$ & Yes & 104 & 55 & $\begin{array}{l}\text { UIP } 72 \% \\
\text { NSIP } 73 \%\end{array}$ & $\begin{array}{l}\text { UIP } 46 \% \\
\text { NSIP } 41 \%\end{array}$ & $\begin{array}{l}\text { UIP } 33 \\
\text { NSIP } 56\end{array}$ & TLCO $35 \%$ predicted: early mortality \\
\hline Collard ${ }^{22}$ & Yes & 81 & 61 & UIP $67 \%$ & UIP $52 \%$ & 51 & $\begin{array}{l}\text { Reduced survival: } 10 \% \text { drop in FVC } \\
6 \text { months }\end{array}$ \\
\hline Flaherty $^{21}$ & Yes & 80 & 62 & $\begin{array}{l}\text { UIP } 67 \% \\
\text { NSIP } 71 \%\end{array}$ & $\begin{array}{l}\text { UIP } 50 \% \\
\text { NSIP } 48 \%\end{array}$ & 69 (total group) & $\begin{array}{l}\text { Reduced survival: } 10 \% \text { drop in FVC/ } \\
6 \text { months }\end{array}$ \\
\hline
\end{tabular}

Subset refers to whether the authors specified the histological subset studied.

Age and FVC/TLCO are median values; survivals are mean values.

LF, lung function; $F E V_{1}$, forced expiratory volume in 1 second; FVC, forced vital capacity; TLC, total lung capacity; TLCO, carbon monoxide transfer factor; UIP, usual interstitial pneumonia; NSIP; non-specific interstitial pneumonia.

predicted TLCo gave an area of 0.8 (CI 0.7 to 0.9 ) and HRCT fibrosis score gave an area of 0.86 (CI 0.77 to 0.95 ). It was shown that a gas transfer factor of $<39 \%$ of predicted combined with HRCT scores had an $80 \%$ sensitivity and specificity for predicting death within 2 years. This allowed the observation of a simple measure of TLCO to be associated with a specific limited time frame of survival. Identification of a threshold value associated with increased mortality serves as the basis for a distinction between advanced and limited disease (fig 1).

The concept of advanced IPF was corroborated by the work of Latsi et al. ${ }^{20}$ In a retrospective study of 104 patients with a histologically confirmed diagnosis, determinants of early mortality at presentation and mortality after 6 months of follow up were studied. In patients dying within 2 years of presentation, the median TLCO was 39\% of the predicted value. These authors present patients with advanced disease as an "early mortality" group in whom physiology was the best determinant of

\begin{tabular}{|c|c|}
\hline $\begin{array}{c}\text { ADVANCED DISEASE } \\
\text { TLCO }<39 \% \\
\text { predicted }\end{array}$ & LIMITED DISEASE \\
& TLCO $>40 \%$ \\
$\begin{array}{c}\text { Refer for transplant } \\
\text { if appropriate } \\
\text { candidate }\end{array}$ & $\begin{array}{c}\text { PROGRESSIVE } \\
\text { DISEASE }\end{array}$ \\
FVC fall $>10 \%$
\end{tabular}

Figure 1 A classification of IPF based on simple lung function criteria. TLCO, carbon monoxide transfer factor; FVC, forced vital capacity. survival. A key observation in this study is that a subgroup of patients with severely reduced Tuco, defined as $<35 \%$ of predicted, had a survival time of less than 2 years irrespective of whether they had UIP or NSIP. Those with a TLCO of $>35 \%$ of predicted had a $65 \%$ survival at 3 years. This emphasises that, once a certain threshold of physiological impairment is reached, mortality is increased.

As lung function is the primary investigation performed by pulmonologists, patients may therefore be defined as having advanced disease (TLCO $<39 \%$ of predicted), allowing the potential identification of patients with poor early survival. Although FVC is predictive of survival in univariate modelling, it does not maintain its effect in multivariate analysis. ${ }^{21}$ The severity of IPF is therefore best graded by TLCO estimation. For patients with limited disease (TLCo $>40 \%$ of predicted), longer survival is more likely. It is in this latter group that serial lung function studies have particular prognostic value.

\section{LUNG FUNCTION AND DISEASE PROGRESSION}

ROC curve analysis highlights the fact that TLCO is superior to FVC for evaluating disease severity. ${ }^{19}$ In contrast, a change in FVC may be the most reliable simple lung function variable to highlight disease progression. When appraising lung function studies of disease progression in IPF, three points deserve consideration: the coefficient of variation of the test, the baseline from which the change occurs, and the time scale used to determine change.

The intertest variation has been widely studied. A $10 \%$ change in FVC is required accurately to reflect a change in vital capacity. Using TLCO requires a change of $15 \%$ or more. Consequently, the baseline from which change occurs is vital to observe. Because many patients with IPF present with a TLCO of $<39 \%$ of predicted, a further $15 \%$ fall from baseline is difficult to document. Individuals require adequate pulmonary reserve to exhibit a change in that parameter. Inadequate reserve may explain why a significant proportion of patients fail to show evidence of lung function progression. Patients with limited disease or adequate pulmonary reserve therefore lend themselves to evaluation of disease progression.

The time required to observe a change in lung function is also critical. As the mean survival of some groups of patients may be as low as 2.5 years, a prolonged period of observation of, for example, 1 year biases a study towards patients with favourable survival and limited disease. Hanson et al ${ }^{13}$ were the first to study the change in lung function over 1 year. They studied 58 patients and evaluated the influence of a $10 \%$ change in FVC and a $20 \%$ change in TLCo. This cohort had favourable characteristics including a mean age of 55 years and a mean survival of 88 months. The mean survival of patients exhibiting a change $(24 \%$ of the total) in FVC was 2.5 years. The mean survival of patients exhibiting a change was also 2.5 years in Tlco $(22 \%$ of the total.)

Acknowledging this, two recent publications progress the strategy described by Hanson et al. ${ }^{13}$ Firstly, Collard et al, ${ }^{22}$ in a study of 81 patients with UIP, evaluated change in lung function over both 6 and 12 months. The median 
survival of the patients subject to 6 month evaluation was 4.8 years and 6.2 years for those studied at 12 months. The mean TLCo of the group was $52 \%$ of predicted. Changes in TLC \% predicted, FVC \% predicted, and TLCO \% predicted over 6 months predicted survival. Of these, the change in FVC \% predicted was the best predictor. Flaherty et $a^{21}$ studied 109 patients, 80 of whom had UIP and 29 had NSIP. The mean TLCO of the group was 50\% of predicted. $32 \%$ of patients had a fall of $>10 \%$ in FVC and $49 \%$ of patients remained within 10\% of baseline. On multivariate analysis, controlling for histological subgroups and baseline lung function, a change in FVC over 6 months was an independent risk factor for mortality. Both studies included patients with preserved TLCO in the region of $50 \%$ of predicted. ${ }^{21} 22$

Changes in TLCO are an alternative measure of disease progression. Latsi et $a l^{20}$ observed a higher mortality in patients with a decline in TLCO at 6 and 12 months, whether trends were quantified numerically or categorically. However, repeat TLCO measurements can be difficult to standardise, explaining the need for a greater change in TLCO than in FVC in order to categorise deterioration. In the study by Latsi et al, serial TLCo trends had only a minimal prognostic advantage over serial FVC trends and the analysis included a significant subset of patients with advanced disease. In the recently published interferon gamma-lb treatment study only $14 \%$ of 300 patients with a mean TLCO of $37 \%$ were defined as having disease progression based on a $15 \%$ change in TLCO (Bill Bradford, personal communication). ${ }^{23}$

Therefore the authors favour classification of disease progression based on change in FVC at 6 months rather than 1 year because this allows the early identification of progressive disease. However, in patients with limited disease the potential value remains of reevaluating progression at 1 year, as demonstrated by Flaherty and Latsi. ${ }^{20} 21$ Re-evaluation at 12 months may be particularly important in the context of a "marginal" decline in FVC of 5-10\%, which may reflect either measurement variation or genuine disease progression. Thus, the definition of disease progression using change over 6 months should not obscure the need to refine prognostic evaluation at 1 year and at least 6 monthly intervals thereafter.

\section{BENEFITS AND DISADVANTAGES OF A CLASSIFICATION}

The potential benefits of a classification based on lung function are substantial. There is a critical need for a classification based on lung function for a condition in which it is difficult to acquire tissue. It would standardise nomenclature and facilitate entry into emerging treatment studies. It may also optimise referral for lung transplantation. A limited window of opportunity exists to refer IPF patients for lung transplantation. The short transplant window is reflected by the high mortality rate in patients with IPF awaiting lung transplantation. ${ }^{24}$ The proposed classification, particularly based on the concept of advanced disease, may facilitate more accurate referral, the time of listing being determined by local organ availability.

Although a tentative and provocative first step, there are potential limitations to the proposed classification. It must be acknowledged that the data presented by Mogulkoc and Latsi are retrospective and should ideally be validated by a prospective evaluation. Furthermore, Thabut and Fournier ${ }^{25}$ emphasise weaknesses with reference to the definition of disease progression based on a $10 \%$ change in FVC. For instance, a change in FVC from $90 \%$ predicted to $80 \%$ predicted is not clinically comparable to a change from $60 \%$ to $50 \%$. There is also an inherent difference between group data and the individual patient. Although group data show that $46 \%$ of patients who exhibit a $10 \%$ fall may survive 5 years, this does not equate with an individual patient having a $46 \%$ chance of surviving 5 years.

It must also be recognised while monitoring disease progression that only a proportion of patients may exhibit a change in lung function. In the study by Flaherty et al, 32\% of patients had a fall of $>10 \%$ in FVC while $49 \%$ of patients remained within $10 \%$ of baseline. ${ }^{21}$ In the interferon gamma-lb treatment study, $25 \%$ of patients were defined as having disease progression based on a change in FVC. ${ }^{23}$ To address this, specialist centres have developed composite indices containing a mixture of parameters, with and without imaging data. ${ }^{26}{ }^{27}$ Preliminary analysis suggests that such scoring systems may be more accurate prognostically than individual lung function variables. However, these scoring systems may not be easily applicable to the broader community of non-specialist centres, especially when exercise testing and radiographic profusion scores are included. The focus should therefore be firstly to emphasise the need for staging based on lung function tests. Although a lung function classification is a first step, in the future HRCT data and simple field exercise tests such as the 6 minute walk test may provide complementary data. ${ }^{28}$ The proposed lung function schema provides a trigger for discussion and a framework from which additional simple and pragmatic markers of progressive disease can be identified.

\section{ACKNOWLEDGEMENTS}

The authors acknowledge the Irish Lung Fibrosis Association, the University of Michigan Fibrotic Lung Disease Network, and the Brompton Interstitial Lung Disease Group

Thorax 2005;60:270-273.

doi: $10.1136 /$ thx.2004.035436

\section{Authors' affiliations}

J J Egan, The Mater Misericordiae Hospital and St Vincent's University Hospital, The Conway Institute, Dublin Molecular Medicine Center, University College Dublin, Ireland F J Martinez, Taubman Center 3916, 1500 E Medical Center Dr, Ann Arbor, Ml 481090360, USA

A U Wells, Interstitial Lung Disease Unit, Emmanuel Kaye Building, Manresa Road, London SW6 LR6, UK

T Williams, Alfred Hospital, Monash

University, Melbourne, Australia

Correspondence to: Dr J Egan, Advanced Lung Disease and Irish National Lung Transplant Program, The Mater Misericordiae Hospital and St Vincent's University Hospital, The Conway Institute, Dublin Molecular Medicine Center, University College Dublin, Ireland; jegan@mater.ie

Conflict of interest: none

\section{REFERENCES}

1 American Thoracic Society/European Respiratory Society. International multidisciplinary consensus classification of the idiopathic interstitial pneumonias. Am J Respir Crit Care Med 2002;165:277-304.

2 Mogulkoc N, Brutsche MH, Bishop PW, et al. Pulmonary (99m)TC-DTPA aerosol clearance and survival in usual interstitial pneumonia (UIP). Thorax 2001;56:916-23.

3 Utz JP, Ryu JH, Douglas WW, et al. High short term mortality following lung biopsy for usual interstitial pneumonia. Eur Respir 2001;17:175-9

4 Raghu G, Mageto YN, Lockhart D, et al. The accuracy of the clinical diagnosis of new-onset idiopathic pulmonary fibrosis and other interstitial lung disease: a prospective study. Chest 1999;116:1168-74.

5 Aziz ZA, Wells AU, Hansell DM, et al. HRCT diagnosis of diffuse parenchymal lung disease; inter-observer variability. Thorax 2004;59:506-11.

6 Estenne M, Maurer JR, Boehler A, et al. Bronchiolitis obliterans syndrome 2001: an update of diagnostic criteria. J Heart Lung Transplant 2002;21:297-310.

7 Vestbo J, Lange P. Can GOLD stage 0 provide information of prognostic value in chronic obstructive pulmonary disease. Am J Respir Crit Care Med 2002;166:329-32.

8 Alhamad EH, Lynch JP, Martinez FJ. Pulmonary function in interstitial lung disease: what role do they have? Clin Chest Med 2001:715-50.

9 Hubbard R, Johnston I, Britton J. Survival in patients with cryptogenic fibrosing alveolitis. Chest 1998;113:396-400.

10 Schwartz DA, Helmers RA, Galvin JR, et al Determinants of survival in idiopathic pulmonary fibrosis. Am J Respir Crit Care Med 1994; 149:450-4. 
11 Erbes R, Schaberg T, Loddenkemper R. Lung function tests in patients with idiopathic pulmonary fibrosis. Chest 1997;111:51-7.

12 Schwartz DA, Van Fossen DS, Davis CS, et al Determinants of progression in idiopathic pulmonary fibrosis. Am J Respir Crit Care Med 1994; 149:444-9.

13 Hanson D, Winterbauer RH, Kirtland SH, et al. Changes in pulmonary function test results after 1 year of therapy as predictors of survival in patients with idiopathic pulmonary fibrosis. Chest 1995; 108:305-10.

14 Katzenstein AA, Myers JL. Idiopathic pulmonary fibrosis, clinical relevance of pathologic classification. Am J Respir Crit Care Med 1998;157:1301-15.

15 Katzenstein AL, Fiorelli RF. Nonspecific interstitia pneumonia/fibrosis: histologic features and clinical significance. Am J Surg Pathol 1994; 18:136-47.

16 Perez A, Rogers RM, Dauber JH. The prognosis of idiopathic pulmonary fibrosis. Am J Respir Cell Mol Biol 2003;29:s19-26.

17 Gay SE, Kazerooni EA, Toews GB, et al. Idiopathic pulmonary fibrosis: predicting response to therapy and survival. Am J Respir Crit Care Med 1998;157:1063-72.

18 Hanley J, McNeil B. The meaning and use of the area under a receiver operating characteristic (ROC) curve. Radiology 1982;144:892-900.

19 Mogulkoc N, Brutsche MH, Bishop PW, et al. Pulmonary function in idiopathic pulmonary fibrosis and referral for lung transplantation. Am J Respir Crit Care Med 2001;164:103-8.

20 Latsi PI, du Bois RM, Nicholson AG, et al. Fibrotic idiopathic interstitial pneumonia: the prognostic value of longitudinal functional trends. Am J Respir Crit Care Med 2003;168:510-1.

21 Flaherty KR, Mumford JA, Murray S, et al. Prognostic implications of physiologic and radiographic changes in idiopathic interstitia pneumonia. Am J Respir Crit Care Med 2003; 168:543-8.

22 Collard HR, King TE, Bucher B, et al. Change in clinical and physiological variables predict survival in idiopathic pulmonary fibrosis. Am J Respir Crit Care Med 2002; 168:538-42.

23 Raghu G, Brown KK, Bradford WZ, et al. A placebo-controlled trial of interferon gamma- $1 \mathrm{~b}$ in patients with idiopathic pulmonary fibrosis. N Engl J Med 2004;350:125-33.

24 Hosenpud JD, Bennett LE, Keck BM, et al. Effect of diagnosis on survival benefit of lung transplantation for end-stage lung disease. Lancet 1998;351:24-7.

25 Thabut G, Fournier M. Prognosis in idiopathic pulmonary fibrosis. Am J Respir Crit Care Med 2004; 169:1075-6

26 King TE, Tooze JA, Swarz MI, et al. Predicting survival in idiopahtic pulmonary fibrosis. Scoring system and survival model. Am J Respir Crit Care Med 2001;164:1171-81.

27 Wells AU, Desai SR, Rubens MB, et al. Idiopathic pulmonary fibrosis: a composite physiologic index derived from disease extent observed by computed tomography. A J Respir Crit Care Med 2003;176:962-9.

28 Lama VN, Flaherty KR, Toews GB, et al. Prognostic value of desaturation during a 6-minute walk test idiopathic interstitial pneumonia. Am J Respir Crit Care Med 2003; 168: 1084-90.

29 Moloney E, Clayton N, Mukergee S, et al. Shutte walk test in idiopathic pulmonary fibrosis. Respir Med 2003;97:682-7.

Online First

\section{Online First in Thorax}

\section{J A Wedzicha, S L Johnston, D M Mitchell}

W e are pleased to announce that Thorax is about to start posting all original articles on its website in an Online First section (http:// www.thoraxjnl.com) shortly after acceptance and before the papers are published in the print version of the journal. Although the time from acceptance to publication in Thorax is relatively short, this initiative is a welcome contribution. An Online First programme was introduced by the British Medical Journal in December 2003, ${ }^{1}$ followed by other specialist journals from the BMJ Publishing Group. ${ }^{2}$ All original articles have also been posted early after acceptance by the American Journal of Respiratory and Critical Care Medicine for some time. ${ }^{3}$

Authors want their research studies to be published as soon as possible after acceptance so that their important scientific and clinical findings can be cited and incorporated into practice. However, there are inevitable delays between acceptance of an article and its appearance in the print version of the journal. Online First in Thorax will allow research work to be available much faster to the research community; manuscripts that have not yet been finally edited by our technical editor will be posted on the website.

With the introduction of Online First, authors will be asked to check their papers carefully after acceptance and then the unedited pdf proof of the manuscript will be posted. The paper will be identified by its unique number-the digital object identifier (DOI) - which will appear at the top of the pdf and will be used to cite the article. Articles published Online First will also be indexed by PubMed early after online publication and will be available when searching for papers using search engines such as PubMed and Google. The final version of the article will be edited by the technical editor and then printed with its DOI number. All versions of the paper will be linked online and will be available to readers.

We hope that the introduction of Thorax Online First will be welcomed by researchers, clinicians, and readers. We encourage you all to log on frequently and to visit the new site to view the recently accepted papers in the journal. Articles can be accessed using the Thorax Online First icon on the Thorax home page. With progress in electronic publishing, important advances in respiratory medicine can now be implemented much more quickly to the benefit of patients all over the world.

Thorax 2005;60:273.

doi: $10.1136 /$ thx.2005.043190

\section{Authors' affiliations}

J A Wedzicha, S L Johnston, D M Mitchell, Thorax Editorial Office, BMA House, Tavistock Square, London WClH 9JR, UK

Correspondence to: Professor J A Wedzicha, Thorax Editorial Office, BMA House, Tavistock Square, London WCIH 9JR, UK;

j.a.wedzicha@qmul.ac.uk

\section{REFERENCES}

1 Smith J. Online firsts. BMJ 2003:327:1302

2 van de Putte $L$. ARD launches an advanced online publication programme. Ann Rheum Dis 2004;63:221.

3 Tobin MJ. The official copy of AJRCCM is posted but not printed. Am J Respir Crit Care Med, 166:905-6. 